\title{
PENGARUH FAKTOR SOSIAL EKONOMI DAN PERILAKU PETERNAK TERHADAP CURAHAN W AKTU KERJA PADA USAHATERNAK AYAM RAS PEDAGING DI KECAMATAN SELEBAR KOTA BENGKULU
}

\author{
Muhamad Nurung \\ Staf Pengajar Jurusan Sosek Fak.Pertanian UNIB
}

\begin{abstract}
This research is aimed at describing the behavior and social economic status of chicken breeder and analysis the influence of social economic factor and behavior to working allocation. Descriptive analysis was use to explain behavior and social economic factors of breeder while multiple regression has applied to analysis the influence of the feeder. The research found that. Breeder's attributes revolving age; household member experience and education are good indicating such as high allocation level and high experience furthermore, it is found that age. number of lobour and cost production are the main factors is founding working allocation and the high education and experience of breeder's is the high working allocation.
\end{abstract}

Key words: Working allocation, social economic factosr.

\section{PENDAHULUAN}

Terbatasnya aspek perilaku petemak berupa; pengetahuan, sikap dan ketrampilan dapat mengakibatkan curahan waktu kerjanya tidak optimal sehingga usahanya menjadi tidak lancar dan sulit berkembang. Rendanya pengetahuan petemak dapat mengakibatkan penggunaan modal kerja tidak efisien, produksi tidak maksimal dan pendapatan rendah. Kemudian mereka sulit menyerap perkembangan teknologi seperti pengobatan ayam dan pemberikan pakan berkwalitas. Sedangkan sikap seperti ragu-rugu, apatis dan tidak respon dalam berusaha dapat menyebabkan petemak sulit mendapatkan keuntungan yang besar. Kemudian rendahnya ketrampilan dalam berusaha dapat menyebabkan petemak tidak dapat bekerja secara efektif dan optimal sehingga produktivitasnya rendah.Ada beberapa faktor sosial ekonomi yang diduga sangat mempengaruhi curahan waktu kerja petemak dalam mengelola usahanya yakni; umur, pendidikan, jumlah anggota keluarga, pengalaman kerja, biaya produksi dan luas kandang. Rendalmya pendidikan, pengalaman, modal kerja dan kecilnya luas kandang, dapat menyebabkan petemak tidak dapat mengalokasikan curahan waktu kerjanya secara optimal. Mestinya petemak menyadari bahwa faktor-faktor tersebut merupakan suatu suatu sumberdaya yang dapat merespon peningakatan curahan waktu kerja. Karena apabila faktor-faktor tersebut tidak digunakan secara tepat selain 
menyebabkan curahan waktu kerja petemak tidak optimal juga bisa menyebabkan petemak menjadi frustasi, malas beketja bahkan tidak bergairah dalam mengelola usahanya.

Masalah perilaku dapat terns berkembang seiring dengan semakin tipisnya peluang peternak khususnya yang ekonominya lemah untuk meningkatkan pengetahuan, sikap dan ketrampilannya, dalam kondisi krisis ekonomi sekarang ini. Kemudian masalah faktor sosial ekonomi dapat berkembang, seiring dengan semakin tingginya tingkat persaingan diantara peternak dalam merebut peluang usaha dan peluang pasar. Oleh karena itu penelitian ini sangat relevan dan diperlukan, sebagai salah satu upaya untuk mendiskripsikan, menganalisa dan menemukan solusi terhadap permasalahan-permasalahan riil yang telah diuraikan di atas.

Tujuan penelitian ini adalah 1) mendiskripsikan kondisi perilaku petemak ayam ras pedaging (aspek; pengetahuan, sikap dan ketrampilan), 2) mendiskripsikan kondisi faktor sosial ekonomi petemak (umur, pendidikan, jumlah anggota keluarga, pengalaman kerja, biaya produksi dan luas kandang) yang digunakan pada usaha temak ayam ras pedaging, 3) menganalisa secara komulatif dan parsial pengaruh faktor so sial ekonomi dan aspek perilaku petemak terhadap curahan waktu kerjanya pada usaha temak ayam ras pedaging.

\section{METODE PENELITIAN}

Daerah penelitian ini ditentukan secara purposive yaitu kecamatan Selebar kota Bengkulu, terdiri dari kelurahan Padang Serai, Kandang dan Pekan Saptu. Penelitian ini menggunakan data primer usaha temak ayam ras pedaging tahun 2004. Data dikumpulkan melalui survei dan wawancara serta pengisian quistioner terhadap 29 responden secara sensus.

Untuk mendiskripsikan kondisi perilaku, faktor sosial ekdnomi dan curahan waktu kerja petemak maka data yang telah dikumpulkan ditabulasi kemudian digolongkan dalam tiga katagori yakni tinggi, sedang dan rendah dan dianalisa dengan metode diskriptif. Data aspek perilaku diukur secara kualitatif dalam bentuk nilai skoring. Sedangkan data faktor sosial ekonomi dan kondisi usaha peternak diukur secara kuantitatif. Cara pengkatagorian diukur melalui rumus sebagai berikut: a) Tinggi, jika (nilai bawah $+2 / 3$ interval) $<$ Skor responden $\sim$ nilai atas, b) Sedang, jika (nilai bawah $+1 / 3$ interval) < Skor responden $\sim$ nilai bawah $+2 / 3$ interval, c) Rendah, jika nilai bawah $\sim$ Skor responden $\sim$ nilai bawah $+1 / 3$ interval.

Untuk mengetahui pengaruh faktor sosial ekonomi dan aspek perilaku peternak terhadap curahan waktu kerja peternak di analisis menggunakan regresi linear berganda dalam bentuk model ekonometrika, sebagai berikut: 
$\operatorname{Ln} Y=\operatorname{Ln} a+a l \operatorname{Ln} X \mid+a 2 \operatorname{Ln} X 2+a 3 \operatorname{Ln} X 3+14 \operatorname{Ln} X i+a s \operatorname{Ln} X s+\| 6 \operatorname{Ln} \sim$

+ a7 DI + a8 D2 + a9 D3 + U I

Keterangan: $Y=$ curahan waktu kerja peternak (Jam/hari), $X I=$ Umur (tahun), $X 2=$ Pendidikan (tahun), X3 = Jumlah tenaga kerja (Orang), = Pengalaman kerja (tahun), Xs = Biaya produksi (Rp/musim), Xt; = Luas kandang (pajang kali lebar $=\mathrm{m} 2$ ), DI = Variabel dummy aspek pengetahuan, D2 = Variabel dummy aspek sikap, D3 = Variabel dummy aspek keterampilan, $a=b$ $=$ Intercep, ai $=$ bi $=$ Parameter dugaan $(i=1,2,3,4,5,6,7,8,9), \mathrm{VI}=\mathrm{V} 2=$ Variabel kesalahan pengganggu

\section{HASIL DAN PEMBAHASAN}

\section{Karakteristik Peternak Ayam Ras Pedaging}

Tabel 1. Katagori dan Rata-rata Umur Petemak Ayam Ras Pedaging di Kecamatan Selebar

\begin{tabular}{clcccc}
\hline No' & \multicolumn{1}{c}{ Katagori } & \multicolumn{1}{c}{ Interval } & $\begin{array}{c}\text { Jumlah } \\
\text { Responden }\end{array}$ & $\begin{array}{c}\text { Persentase } \\
(\%)\end{array}$ & $\begin{array}{c}\text { Rata-rata } \\
(\text { Tahun })\end{array}$ \\
\hline 1 & Tua & $48,3<$ umur $<62$ & 4 & 13,79 & \\
2 & Sedang & $34,7<$ umur $<48,3$ & 11 & 37,93 & 37,6 \\
3 & Muda & $21 \ldots ;$ umur $: ., ; 34,7$ & 14 & 48,28 & \\
\hline & Jumlah & 29 & 100,00 & \\
\hline
\end{tabular}

Sumber: Hasil pengolahan Data Primer Tahun 2004

Rata-rata umur responden 38 tahun, berarti dalam kondisi produktif, karena tenaganya masih kuat bekerja. Kemudian umur paling banyak katagori muda yakni 14 orang $(48,28 \%)$, berarti usaha ternak ayam ras pedaging diminati pemuda di daerah ini. Mereka meyakini usaha tersebut dapat memberikan pendapatan yang besar dalam waktu yang relatif singkat.

\section{Tanggungan Keluarga}

Tabel 2. Katagori dan Rata-rata Jumlah Tanggungan Keluarga (JTK) Petemak Ayam Ras Pedaging di Kecamatan Selebar

\begin{tabular}{cccccc}
\hline No & Katagori & Interval & $\begin{array}{c}\text { Jumlah } \\
\text { Responden }\end{array}$ & $\begin{array}{c}\text { Persentase } \\
(\%)\end{array}$ & $\begin{array}{c}\text { Rata-rata } \\
(\text { Tahun })\end{array}$ \\
\hline 1 & Banyak & $3,7<$ JTK $\ldots ;, 5$ & 6 & 20,69 & \\
2 & Sedang & $2,3<$ JTK $\ldots ; 3,7$ & 9 & 31,03 & 2 \\
3 & Sedikit & $1 \ldots, \ldots$, JTK $\ldots, \ldots ; 2,3$ & 14 & 48,28 & \\
\hline & & 29 & 100,00 & \\
\hline
\end{tabular}

Sumber: Hasil Pengolahan Data Primer Tahun 2004

Tanggungan keluarga paling banyak katagori sedikit yakni 14 orang $(48,28)$ dan rata-rata tanggungan keluarga 2 orang. Hal ini disebabkan karena umumnya mereka belum lama berkeluarga. Kondisi ini mengindikasikan beban biaya hidup keluarga mereka masih rendah, 
sehingga sebagian pendapatan dari usaha ternak dapat digunakan untuk menambah modal usaha.

\section{Anggota Keluarga yang Membantu dalam Usaha Ternak Ayam Ras}

Rata-rata jumlah anggota keluarga yang membantu dalam usaha temak 2 orang dan banyak dalam katagori sedang yakni 14 orang $(48,28 \%)$, Hal ini disebabkan karena umumnya luas kandang petemak ukurail kecil yakni kapasitas 1000-1500 ekor ayam sehingga tidak memerlukan banyak tenaga kelja. Keberadaan kedua orang tersebut cukup membantu dan dapat memperlancar penyelesaian pekeljaan setiap harinya seperti memberipakan, minmn dan kegiatan pada saat panen.

Tabel 3. Katagori dan Rata-rata Jumlah Anggota Keluarga (JAK) yang Membantu Usaha Petemak Ayam Ras Pedaging di Kecamatan Selebar

\begin{tabular}{|c|c|c|c|c|c|}
\hline No & Katagori & Interval & $\begin{array}{c}\text { Jumlah } \\
\text { Responden }\end{array}$ & $\begin{array}{c}\text { Persentase } \\
(\%)\end{array}$ & $\begin{array}{c}\text { Rata-rata } \\
\text { (Tahun) }\end{array}$ \\
\hline 1 & Banyak & $2,3<$ JAK 3 & 5 & 17,24 & \\
\hline 2 & Sedang & $1,7<$ JAK 2,3 & 14 & 48,28 & 2 \\
\hline 3 & Sedikit & $1<\operatorname{JAK} 1,7$ & 10 & 34,481 & \\
\hline & \multicolumn{2}{|c|}{ Jumlah } & 29 & 100,00 & \\
\hline
\end{tabular}

Sumber: Hasil Pengolahan Data Primer Tahun 2004

\section{Pengalaman Betemak Ayam Ras Pedaging}

Rata-rata pengalaman usaha temak 5,8 tahun dan paling banyak katagori sedang yakni 16 orang $(55,17 \%)$. Hal ini disebabkan karena umur mereka umumnya masih muda. Namun pengalaman yang dimiliki sudah dapat diandalkan. Karena mereka cukup terampil dalam bekerja seperti memberi pakan dan minmn seta mengobati ayam sakit.

Tabel 4. Katagori dan Rata-rata Pengalaman (P) Betemak Ayam Ras Pedaging di Kecamatan Selebar

\begin{tabular}{cccccc}
\hline No & Katagori & Interval & $\begin{array}{c}\text { Jmnlah } \\
\text { Responden }\end{array}$ & $\begin{array}{c}\text { Persentase } \\
(\%)\end{array}$ & $\begin{array}{c}\text { Rata-rata } \\
\text { (Tahun) }\end{array}$ \\
\hline 1 & Tinggi & $9,8<\mathrm{P} 14$ & 5 & 17,24 & \\
2 & Sedang & $5,7<\mathrm{P} \ldots, 9,8$ & 16 & 55,17 & 5,8 \\
3 & Rendah & 1,5 P 5,7 & 8 & 27,591 & \\
\hline & & Jumlah & 29 & 100,00 & \\
\hline
\end{tabular}

Sumber: Hasil Pengolahan Data Primer Tahun 2004

\section{Pendidikan}

Pendidikan petemak terdiri dari; saljana 1 orang $(3,45 \%)$, tanlat SD 5 orang $(17,24 \%)$, tamat SMP 9 orang $(31,03 \%)$ dan tamat SMA 14 orang $(48,28 \%)$. Kondisi ini menoojukkan tingkat 
pendidikan yang dimiliki tergolong tinggi karena banyak yang tamat SMA. Melalui pendidikan tersebut petemak dapat memahanli petunjuk teknis dalam mengelola usalla temak.

\section{Kondisi Kandang Ayam}

Tabel 5. Rata-rata Panjang, Lebar, Luas, Umur dan Biaya Pembuatan Kandang Usaha Temak Ayam Ras Pedaging di Kecamatan Selebar.

\begin{tabular}{cccc}
\hline No & Uraian & Satuan & Rata-rata \\
\hline 1 & Panjang & Meter & 31,38 \\
2 & Lebar & Meter & 5,43 \\
3 & Luas & Mete & 183,83 \\
4 & Umur Pemakaian Kandang & Tahun & 4,45 \\
\hline 5 & Biaya Pembuatan Kandang & Rp/unit & $5.706 .896,6$ \\
\hline
\end{tabular}

Sumber: Hasil Pengolahan Data Primer Tahun 2004

Rata-rata panjang kandang 31,38 meter, lebar 5,43 meter dan luas kandang 183,83 meter. Kandang tersebut tergolong besar karena dapat memelihara ayam sampai 2500 ekor. Namun peternak rata-rata hanya memelihara 1600 ekor sehingga kapasitas kandang belum maksimal. Konsekuensi kandang yang besar adalah biaya pembuatannya juga besar yakni Rp 5.706.896,6 per unit. Biaya tersebut dipengaruhi upah pembuatannya, jumlah dan harga bahan seperti atap, kayu tiang, papan dan bambu serta peralatan kandang seperti tempat minum, tempat makan dan lampu.

\section{Curahan Waktu Kerja}

Tabel 6. Rata-rata Curahan Waktu Kerja dan dan Upah Tenaga Kerja yang Membantu pada Usaha Ternak Ayam Ras Pedawg di Kecamatan Selebar

\begin{tabular}{ccccc}
\hline No & Jenis Pekeriaan & $\begin{array}{c}\text { Rata-rata Hari } \\
\text { Kerja }(\mathrm{HOK})\end{array}$ & $\begin{array}{c}\text { Rata-rata } \\
\text { Tenaga Keria }\end{array}$ & $\begin{array}{c}\text { Rata-rata TK } \\
\text { Keluarga Membantu }\end{array}$ \\
\hline 1 & Persiapan kandang & 3,05 & & 2 \\
2 & Pemeliharaan ayam & 57,20 & 3 & \\
3 & Pemanenan ayam & 2,80 & & \\
\hline Jumlah curahan waktu kerja & 63,05 & & \\
\hline
\end{tabular}

Sumber: Hasil Pengolahan Data Primer Tahun 2004

Rata-rata jumlah tenaga kerja untuk setiap kandang 3 orang, terdiri dari 1 orang pemilik dan 2 orang tenaga kerja pembantu. Pekerjaan yang memerlukan curahan waktu kerja paling banyak adalah pemeliharaan ayam, yakni rata-rata 57,2 HOK. Hal ini disebabkan karena selama pemeliharaan dilakukan pekerjaan seperti memberikan; pemanasan ruang, pakan, minum dan obat-obatan. 


\section{Biaya Produksi}

\begin{tabular}{|c|c|c|c|}
\hline No & Jenis Biaya & Rata-rata Biaya (Rp) & Persentase \%) \\
\hline 1 & Biaya bibit & $4.576 .896,6$ & 24,92 \\
\hline 2 & Biaya pakan & $12.853 .241,0$ & 69,98 \\
\hline 3 & Biaya obat-obatan & $172.775,9$ & 0,94 \\
\hline 4 & Biaya minyak tanah & $179.465,5$ & 0,98 \\
\hline 5 & Upah tenaga kerja yang membantu & $424.137,9$ & 2,31 \\
\hline 6 & Penyusutan peralatan & $161.375,9$ & 0,87 \\
\hline & Total Biaya Produksi & $18.367 .892,8$ & 100,00 \\
\hline
\end{tabular}

Sumber: Hasil Pengolahan Data Primer Tahun 2004

Rata-rata biaya produksi Rp18.367.892,8 dan tergolong tinggi. Meskipun tinggi, biaya tersebut dapat diatasi karena dibantu oleh pengusaha dalam pengadaan; bibit, pakan dan obatobatan, dengan syarat produksi ayam dijual kepada pengusaha tersebut. Tingginya biaya produksi dipengaruhi oleh jumlah dan harga; pakan, bibit dan obat-obatan yang digunakan. Biaya yang paling besar adalah pakan yakni Rp12.853.241,- atau 69,98\% dari rata-rata total biaya. Besarnya biaya tersebut disebabkan karena banyaknya pakan yang diberikan sejak ayam masuk kandang sampai dengan saat mau panen atau selama pemeliharaan yakni 40 sampai 45 hari.

\section{PERILAKU PETERNAK}

\section{Aspek Pengetahuan Peternak dalam Usaha Ternak Ayam Ras}

Tabe18. Katagori HasH Skoring Aspek Pengetahuan (D]) Peternak Ayam Ras di Kecamatan Selebar

\begin{tabular}{cccccc}
\hline No & Katagori & Interval & Jumlah Resp. & Persentase (\%) & Rata-rata \\
\hline I & Tinggi & $23,3<$ D] s 30 & 28 & 96,55 & \\
2 & Sedang & $16,7<$ D] s 23,3 & 1 & 3,45 & 28,9 \\
3 & Rendah & 10 s D] s 16,7 & 0 & 0,00 & \\
\hline & Jumlah & 29 & 100,00 & \\
\hline
\end{tabular}

Sumber: Hasil Pengolahan Data Primer Tahun 2004

Rata-rata nilai pengetahuan peternak 28,9, masuk dalam katagori tinggi. Berarti

Pengetahuan peternak cukup mendukung dalam mengelola usahanya. Tingginya pengetahuan tersebut disebabkan karena mereka rajin belajar, banyak bertanya atau berkonsultasi, dapat membaca buku, majalah dan brosur peternakan. Petemak banyak memiliki aspek pengetahuan pada katagori tinggi yakni 28 responden atau 96,55\%. Berarti umumnya peternak telah memiliki pengetahuan yang diperlukan, misalnyajenis bibit dan pakan kualitasnya baik serta penggunaan beberapajenis obat-obatan. 
Tabel 9. Rata-rata Hasil Skoring Aspek Pengetahuan Petemak Ayam Ras di Kecamatan Selebar

\begin{tabular}{clcccccc}
\hline \multirow{2}{*}{ No Aspek pengetahuan } & \multicolumn{7}{c}{ Rata-rata Skoring } \\
& \multicolumn{1}{c}{ Sangat Mengerti } & Kurang Mengerti & Tidak Mengerti \\
\hline 1 & Bibit & 1,86 & $62,0 \%$ & 0,69 & $34,5 \%$ & 0,03 & $3,0 \%$ \\
2 & Pakan & 2,17 & $72,3 \%$ & 0,55 & $27,7 \%$ & 0,00 & $0,0 \%$ \\
3 & Obat-obatan & 2,59 & $86,3 \%$ & 0,21 & $10,4 \%$ & 0,03 & $3,0 \%$ \\
4 & Ciri-ciri ayam sehat/sakit & 3,00 & $100,0 \%$ & 0,00 & $0,0 \%$ & 0,00 & $0,0 \%$ \\
5 & Jenis penyakit & 2,69 & $89,7 \%$ & 0,21 & $10,3 \%$ & 0,00 & $0,0 \%$ \\
6 & Kebersihan kandang & 3,00 & $100,0 \%$ & 0,00 & $0,0 \%$ & 0,00 & $0,0 \%$ \\
7 & Pengaruh; bibit, pakan, obat- & 3,00 & $100,0 \%$ & 0,00 & $0,0 \%$ & 0,00 & $0,0 \%$ \\
& obatan dan modal thp produksi & & & & 0,00 & \\
8 & Analisa usaha & 2,90 & 96,5 & 0,07 & $3,5 \%$ & 0,00 & $0,0 \%$ \\
9 & Modal usaha & 3,00 & $100,0 \%$ & 0,00 & $0,0 \%$ & 0,00 & $0,0 \%$ \\
\hline 10 & Resiko usaha & 2.79 & $93,0 \%$ & 0,14 & $7,0 \%$ & 0,00 & $0,0 \%$ \\
\hline
\end{tabular}

Sumber: Hasil Pengolahan Data Primer Tahun 2004

Aspek pengetahuan tentang usaha temak ayam ras yang sangat dimengerti peternak adalah ciri-ciri ayam sehatlsakit, pentingnya kebersihan kandang, pengaruh penggunaan bibit, pakan, obat-obatan dan modal terhadap produksi serta modal us aha. Masing-masing nilainya $100 \%$, berarti; pengetahuan. petemak pada aspek tersebut tidak perlu diragukan dalam mengelola usahanya. Berhasilnya peternak mencapai tingkat kehidupan ayam sebesar $80 \%$, diyakini berkaitan dengan aspek pengetahuan tersebut.

\section{Aspek Sikap Peternak dalam Usaha Ternak Ayam Ras}

Tabel I0. Katagori Hasil Skoring Aspek Sikap (D2) Petemak Ayam Ras di Kecamatan Selebar

\begin{tabular}{cccccc}
\hline No & Katagori & Interval & Jumlah Resp. & Persentase (\%) & Rata-rata \\
\hline 1 & Setuju & $23,3<\mathrm{D} 2 \ldots ; 30$ & 28 & 96,55 & \\
2 & Kurang setuju & $16,7<\mathrm{D} 2 \ldots ; 23,3$ & 1 & 3,45 & 26,5 \\
3 & Tidak setuju & $10 \ldots ;$ D2 $: . ; 16,7$ & 0 & 0,00 & \\
\hline & & 29 & 100,00 & \\
\hline
\end{tabular}

Sumber: Hasil pengolahan Data Primer Tahun 2004

Nilai sikap peternak 26,5, tergolong katagori setuju. Berarti umumnya petemak di daerah ini mendukung dan menerima upaya-upaya pengembangan usaha temak ayam ras. Sikap tersebut timbul karena peternak menyadari dan menyakini bahwa usaha temak dapat dijadikan sebagai usaha pokok dalam menghidupi keluarganya. Sikap tersebut ditunjukkan pula oleh seriusnya mereka dalam bekerja. Kemudian mereka yakin; usaha ternak akan berkembang dimasa datang seiring dengan semakin banyaknya jumlah penduduk yang memerlukan konsumsi daging ayam. 
Tabel 11. Rata-rata Hasil Skoring Aspek Sikap Petemak Ayam Ras di Kecamatan Selebar

\begin{tabular}{|c|c|c|c|c|c|c|c|}
\hline \multirow{2}{*}{ No } & \multirow{2}{*}{ Aspek Sikap } & \multicolumn{6}{|c|}{ Rata-rata Skoring } \\
\hline & & \multicolumn{2}{|c|}{ Sangat Setuju } & \multicolumn{2}{|c|}{ Kurang Setuju } & \multicolumn{2}{|c|}{ Tidak Setuju } \\
\hline 1 & Usaha ternak; keinginan sendiri & 2,28 & $76,0 \%$ & 0,48 & $24,0 \%$ & 0,00 & $0,0 \%$ \\
\hline 2 & Daya tarik usaha temak & 2,48 & $83,0 \%$ & 0,34 & $17,0 \%$ & 0,00 & $0,0 \%$ \\
\hline 3 & Keseriusan dalam bekeda & 3,00 & $100,0 \%$ & 0,00 & $0,0 \%$ & 0,00 & $0,0 \%$ \\
\hline 4 & Perasaan dalam bekerja & 2,48 & $83,0 \%$ & 0,34 & $17,0 \%$ & 0,00 & $0,0 \%$ \\
\hline 5 & Keyakinan terhadap usaha ternak & 2,07 & $69,0 \%$ & 0,62 & $31,0 \%$ & 0,00 & $0,0 \%$ \\
\hline 6 & Kesesuaian harapan; pendapatan & 1,67 & $60,0 \%$ & 0,80 & $40,0 \%$ & 0,00 & $0,0 \%$ \\
\hline 7 & $\begin{array}{l}\text { Kesesuaian pengetahuan dan } \\
\text { keterampilan }\end{array}$ & 2,20 & $72,5 \%$ & 0,55 & $27,5 \%$ & 0,00 & $0,0 \%$ \\
\hline 8 & $\begin{array}{l}\text { Keyakinan terhadap prospek usaha } \\
\text { temak }\end{array}$ & 2,69 & $89,5 \%$ & 0,07 & $3,5 \%$ & 0,07 & $7,0 \%$ \\
\hline 9 & $\begin{array}{l}\text { Keyakinan terhadap perkembangan } \\
\text { usaha temak }\end{array}$ & 0,82 & $27,5 \%$ & 1,31 & $65,5 \%$ & 0,07 & $7,0 \%$ \\
\hline 10 & $\begin{array}{l}\text { Keyakinan terhadap minat } \\
\text { masyarakat pada usaha temak }\end{array}$ & 0,62 & $20,5 \%$ & 1,45 & $72,5 \%$ & 0,07 & $7,0 \%$ \\
\hline
\end{tabular}

Sumber: Hasil Pengolahan Data Primer Tahun 2004

Aspek sikap petemak yang menunjukkan sangat setuju terhadap pengembangan usaha temak ayam ras adalah seriusnya mereka bekerja. Nilainya 100\%, berarti mereka sepenuhnya mencurahkan waktu, tenaga, biaya dan pikiran terhadap usahanya. Seriusnya mereka bekerja didasari oleh keinginan untuk menghasilkan produksi dan pendapatan yang maksimal. Disamping itu mereka sadar bahwa usaha ternak memerlukan perhatian yang serius karena memiliki resiko tinggi seperti kematian ayam.

\section{Aspek Keterampilan Peternak dalam Usaha Ternak Ayam Ras}

Tabel.12. Katagori Hasil Skoring Aspek Keterampilan (D3) Peternak Ayam Ras di Kecamatan Selebar

\begin{tabular}{cccccc}
\hline No & Katagori & Interval & Jumlah Resp. & Persentase (\%) & Rata-rata \\
\hline 1 & Tinggi & $23,3<$ D3 s: 30 & 29 & 100,00 & \\
2 & Sedang & $16,7<$ D3 s: 23,3 & 0 & 0,00 & 29,3 \\
3 & Rendah & 10 s: D3 s: 16,7 & 0 & 0,00 & \\
\hline & Jumlah & 29 & 100,00 & \\
\hline
\end{tabular}

Sumber: Hasil Pengolahan Data Primer Tahun 2004

Nilai keterampilan peternak 29,3 dan tergolong katagori tinggi. Berarti peternak dapat melakukan pekerjaan yang membutuhkan keterampilan khusus dalam usaha ternak. Misalnya 
mereka terampil membuat dan memperbaiki kandang, membuat campuran makanan dan mengobati ayam. Tingginya keterampilan tersebut disebabkan karena umumnya mereka keturunan keluarga peternak dan setiap hari mengamati pekerjaan-pekerjaan di kandang.

Semua peternak memiliki aspek keterampilan pada katagori tinggi yakni 29 responden atau $100 \%$. Berarti semua peternak terampil bekerja pada usaha ternak. Keterampilan tersebut mereka peroleh karena rajin dan giat bekerja, selalu membenahi diri jika ada kesalahan serta patuh terhadap petunjuk-petunjuk teknis yang diberikan.

Tabel.13. Rata-rata Hasil Skoring Aspek Keterampilan Peternak Ayam Ras di Kecamatan Selebar

\begin{tabular}{clcccccc}
\hline \multirow{2}{*}{ No Aspek Keterampilan } & \multicolumn{9}{c}{ Tinggi } & \multicolumn{2}{c}{ Sata-rata Skoring } \\
& & \multicolumn{2}{c}{ Sedang } & \multicolumn{2}{c}{ Rendah } \\
\hline 1 & Membuat/memperbaiki kandang & 2,07 & 69,5 & 0,55 & $27,5 \%$ & 0,03 & $3,0 \%$ \\
2 & Teknis pengobatan ayam sakit & 3,00 & $100,0 \%$ & 0,00 & $0,0 \%$ & 0,00 & $0,0 \%$ \\
3 & Terlihat kesulitan dalam bekerja & 2,17 & $72,5 \%$ & 0,55 & $27,5 \%$ & 0,00 & $0,0 \%$ \\
4 & Teknis pemberian pakan & 3,00 & $100,0 \%$ & 0,00 & $0,0 \%$ & 0,00 & $0,0 \%$ \\
5 & Memisahkan ayam sehat dan sakit & 3,00 & $100,0 \%$ & 0,00 & $0,0 \%$ & 0,00 & $0,0 \%$ \\
6 & Membuat campuran pakan & 2,89 & $96,5 \%$ & 0,07 & $3,5 \%$ & 0,00 & $0,0 \%$ \\
7 & Menjaga kebersihan kandang & 3,00 & $100,0 \%$ & 0,00 & $0,0 \%$ & 0,00 & $0,0 \%$ \\
8 & Meniaga kesehatan ayam & 2,89 & $96,5 \%$ & 0,07 & $3,5 \%$ & 0,00 & $0,0 \%$ \\
9 & Mengamati perkemb/pertumb ayam & 3,00 & $100,0 \%$ & 0,00 & $0,0 \%$ & 0,00 & $0,0 \%$ \\
10 & Mengatur suhu ruang kandang & 3,00 & $100,0 \%$ & 0,00 & $0,0 \%$ & 0,00 & $0,0 \%$ \\
\hline
\end{tabular}

Sumber: Hasil Pengolahan Data Primer Tahun 2004

Aspek keterampilan yang tergolong tinggi adalah teknik; mengobati ayam sakit, memberi pakan, mernisahkan ayam sehat dan sakit, menjaga kebersihan kandang, mengamati pertumbuhan ayam dan mengatur suhu kandang. Masing-masing nilainya 100\%, berarti keterampilan peternak pada aspek tersebut dapat diandalkan dalam bekerja. Diyakini bahwa; keberhasilan hidup ayam mencapai $80 \%$, berkaitan dengan tingginya keterampilan tersebut.

Pengaruh Faktor Sosial Ekonomi dan Perilaku Terhadap Curahan Waktu Kerja Petemak Ayam Ras Pedaging

Hasil estimasi (Tabel 14) menunjukkan; nilai koefisien detenninasi $(R 2)=0,961$, berarti $96,1 \%$ variasi curahan waktu kerja peternak dapat dijelaskan secara bersama-sama oleh variabel bebas yang digunakan dalam model. Nilai tersebut mendekati $100 \%$, berarti; model yang digunakan ootuk estimasi validitasnya cukup tinggi. Kemudian $\mathrm{F}$ hitung $=51.594$ lebih besar dibandingkan $\mathrm{F}$ tabel pada taraf kepercayaan $99 \%=3,52$, sehingga hipotesa Ha diterima. Berarti; 
secara bersama-sama variabel bebas dalam model berpengaruh nyata terhadap variabel terikat. Diterimanya hipotesa $\mathrm{Ha}$, menoojukkan bahwa untuk meningkatkan curahan waktu kerja perlu mengoptimalkan penggunaan tenaga kerja produktif, pendidikan dan pengalaman kerja sesuai bidang usaha dan biaya produksi cukup tersedia.

Tabel 14. Hasil Estimasi Faktor-Faktor yang Mempengaruhi Curahan Waktu Kerja Petemak Ayam Ras Pedaging di Kecamatan Selebar

\begin{tabular}{|c|c|c|c|c|c|c|}
\hline \multicolumn{7}{|c|}{ REGRESSION ANALYSIS } \\
\hline \multicolumn{7}{|c|}{$\begin{array}{l}\text { LABEL: CURAHAN WAKTU KERJA PETERNAK AYAM RAS } \\
\text { S }\end{array}$} \\
\hline \multicolumn{3}{|c|}{ NUMBER OF CASES: 29 NUMBER } & F VARIABLES: & 10 & & \\
\hline \multicolumn{7}{|c|}{ DEPENDENT VARIABLE: LN YI } \\
\hline VAR. & REGRESSION & OEFFICIENT & STD. ERROR & $\mathrm{T}(\mathrm{DF}=19)$ & PROB. & PARTIAL rA2 \\
\hline LN X2 & $-1.731 \mathrm{E}-03$ & & .080 & -.022 & .98306 & $2.43502 \mathrm{E}-05$ \\
\hline LN X3 & 1.533 & & .141 & 10.862 & .00000 & .8613 \\
\hline LN X4 & -.012 & & .042 & -.278 & .78431 & .0040 \\
\hline LN X5 & 124 & & .106 & 1.170 & .25663 & .0672 \\
\hline LN X6 & -.031 & & .081 & -.382 & .70694 & .0076 \\
\hline 01 & .075 & & .049 & 1.529 & .14282 & .1095 \\
\hline 02 & $1.8256 \mathrm{E}-03$ & & .045 & .041 & .96807 & 8.65908E-05 \\
\hline 03 & -.091 & & .065 & -1.403 & .17674 & .0939 \\
\hline \multicolumn{7}{|c|}{$\begin{array}{ll}\text { CONSTANT } & .575\end{array}$} \\
\hline \multicolumn{3}{|c|}{ STD. ERROR OF EST. $=.105$} & \multicolumn{2}{|c|}{ R SQUARED $=.961$} & & \\
\hline \multirow{2}{*}{\multicolumn{3}{|c|}{ SUM OF SQUARES ANA }} & YSIS OF VARIAI & SE TABLE & & \\
\hline & & & D. F. & MEAN SQUARE & F RATIO & PROB. \\
\hline & RESSION & 5.112 & 9 & .568 & 51.594 & 1. $848 \mathrm{E}-11$ \\
\hline RESIDUAL & & .209 & 19 & .011 & & \\
\hline
\end{tabular}

Sumber: Hasil Pengolahan Data Primer Tahun 2004

\section{Pengaruh Variabel Umur Peternak}

Koefisien regresi umur petemak 0,021, berarti; apabila umur petemak meningkat satu satuan akan mempengaruhi peningkatan curahan waktu kerja petemak sebesar 0,021 kali. Kemudian $t$ hitung $=0,177$ lebih kecil dibandingkan dengan $t$ tabel pada taraf kepercayaan $90 \%=$ 1,746, sehingga terima Ho, berarti; umur berpengaruh tidak nyata terhadap peningkatan curahan waktu ketja. Hasil estimasi ini mengindikasikan bahwa meskipoo umur peternak umumya dalam usia produktif, namun belum menunjukkan intensitas kerja yang tinggi sehingga pengaruhnya terhadap peningkatan curahan waktu kerja masih kecil.

\section{Pengaruh Variabel Pendidikan Peternak}

Koefisien regresi variabel pendidikan petemak $.0,002$, berarti; apabila pendidikan peternak meningkat satu satuan akan mempengaruhi penurunan curahan waktu kerja peternak pada usahanya sebesar 0,002 kali. Kemudian nilai $t$ hitung $=-0,22$ lebih besar dibandingkan 
dengan $t$ tabel pada tarafkepercayaan $90 \%=-1,746$, sehingga terima $\mathrm{Ho}$, berarti; pendidikan petemak berpengarnh tidak nyata terhadap penurunan curahan waktu kerja. Hasil estimasi ini menunjukkan bahwa peternak yang tinggi pendidikannya, maka waktu kerja dimiliki selain digunakan untuk usaha ternak juga digunakan untuk usaha lain seperti berdagang dan bertani.

\section{Pengaruh Variabel Jumlah Tenaga Kerja}

Koefisien regresi jumlah tenaga kerja 1,533, berarti; apabila jumlah tenaga kerja dalam usaha ternak ayam ras meningkat sebesar satu satuan akan mempengaruhi peningkatan curahan waktu kerja peternak sebesar 1,5 kali. Kemudian t hitung $=10,862$ lebih besar dibandingkan dengan $\mathrm{t}$ tabel pada taraf kepercayaan $90 \%=1,746$, sehingga terima hipotesa Ha berarti; jumlah tenaga kerja berpengaruh nyata terhadap peningkatan curahan waktu kerja. Hasil estimasi ini menunjukkan bahwa adanya tambahan tenaga kerja mengakibatkan pekerjaan seperti; membersihkan kandang, memberi makan dan minurn serta pemanenan harns diawasi lebih intensif agar selesai dalam waktu yang lebih cepat dibandingkan kalau dikerjakan sendiri. Tambahan tenaga kerja dapat pula meningkatkan motivasi kerja peternak sehingga curahan waktu kerjanya menjadi meningkat.

\section{Pengaruh Variabel Pengalaman Kerja}

Koefisien regresi pengalaman kerja beternak $-0,012$, berarti; apabila pengalaman kerja beternak meningkat satu satuan akan mempengarnhi penurunan curahan waktu kerjanya sebesar 0,012 kali. Kemudian nilai $t$ hitung $=-0,278$ lebih besar dibandingkan dengan $t$ tabel pada taraf kepercayaan $90 \%=-1,746$, sehingga terima Ho, berarti; pengalaman kerja berpengaruh tidak nyata terhadap penurunan curahan waktu kerja. Hasil estimasi ini menunjukkan; semakin tinggi pengalaman kerja menyebabkan peternak lebih banyak memberikan perintah, pengarahan atau petunjuk kerja kepada pekerjanya sehingga pekerjaan lebih banyak dikerjakan oleh pekerjanya dibandingkan peternak itu sendiri.. Umumnya peternak yang berpengalaman hanya banyak melakukan pengontrolan cara pekerja memberi pakan, minurn dan obat-obatan agar sesuai dengan yang diperintahkan.

\section{Pengaruh Variabel Biaya Produksi}

Koefisien regresi biaya produksi 0,124 , berarti; apabila biaya produksi meningkat satu satuan akan mempengaruhi peningkatan curahan waktu kerja peternak sebesar 0,1 kali. Kemudian $t$ hitung $=1,17$ lebih kecil dibandingkan dengan $t$ tabel pada taraf kepercayaan $90 \%=$ 1,746, sehingga terima $\mathrm{Ho}$, berarti; biaya produksi berpengaruh tidak nyata terhadap peningkatan 
curahan waktu kerja. Hasil estimasi ini menunjukkan bahwa peternak yang modalnya tinggi lebih banyak menggunakan tenaga kelja upahan untuk mengerjakan pekerjaan seperti membangun dan memperbaiki kandang, sehingga curahan waktu kerjanya menjadi rendah. Sedangkan peternak yang modalnya rendah hampir semua pekeljaan dilakukan sendiri dan dibantu oleh tenaga kelja dari keluarga sehingga curahan waktu kerjanya tinggi.

\section{Pengarub Variabel Luas Kandang}

Koefisien regresi luas kandang $-0,031$, berarti; apabila luas kandang yang dimiliki peternak meningkat satu satuan akan mempengaruhi penurunan curahan waktu kerja sebesar 0,031 kali. Kemudian $t$ hitung $=-0,382$ lebih besar dibandingkan dengan $t$ tabel pada taraf kepercayaan $90 \%=-1,746$, sehingga terima $\mathrm{Ho}$, berarti; luas kandang berpengaruh tidak nyata terhadap penurunan curahan waktu kerja. Hasil estimasi ini menunjukkan bahwa; peternak yang memiliki luas kandang besar curahan waktu kerjanya rendah karena mampu membayar lebih banyak tenaga kerja upahan. Sedangkan peternak yang memiliki luas kandang kecil curahan waktu kerjanya tinggi karena modalnya terbatas sehingga tidak banyak menggunakan tenaga kerja upahan.

\section{Pengarub Variabel Pengetabuan Peternak}

Koefisien regresi variabel pengetahuan 0,075 , berarti peternak yang pengetahuannya tinggi tentang usaha ternak ayam ras pedaging, curahan waktu kerjanya lebih tinggi sebesar 0,075 kali dibandingkan dengan peternak yang pengetahuannya rendah. Kemudian $t$ hitung $=1,529$ lebih kecil dibandingkan dengan $\mathrm{t}$ tabel pada taraf kepercayaan $90 \%=1,746$, sehingga terima $\mathrm{Ho}$ berarti; terdapat perbedaan yang tidak nyata antara curahan waktu kelja peternak yang pengetahuannya tinggi dengan peternak pengetahuannya rendah. Hasil tersebut disebabkan karena peternak yang pengetahuannya tinggi selalu mengatur aktivitas kerjanya secara intensif dan teljadwal serta banyak melakukan pekerjaan tambahan seperti mengamati pertumbuhan ayam dan mengontrol kesehatan ayam.

\section{Pengaruh Variabel Sikap Peternak}

Koefisien regresi variabel sikap 0,002, berarti peternak yang sikapnya setuju terhadap pengembangan us aha ternak ayam ras pedaging, lebih tinggi curahan waktu kerjanya 0,002 kali dibandingkan dengan peternak yang sikapnya kurang dan tidak setuju. Kemudian thitung $=0,041$ lebih kecil dibandingkan dengan $\mathrm{t}$ tabel pada taraf kepercayaan $90 \%=1,746$, sehingga terima $\mathrm{Ho}$, berarti; terdapat perbedaan yang tidak nyata antara curahan waktu kerja peternak yang sikapnya 
setuju dengan peternak yang sikapnya kur/Wg dan tidak setuju. Hasil tersebut disebabkan karena petemak yang setuju, telah memiliki pengalaman lebih dari 5 tahun sehingga pengetahuan dan cara kerja sudah baik. Petemak tersebut juga serius dan tekun dalam bekerja serta memiliki keyakinan bahwa usaha temak akan terns berkembang seiring dengan semakin berkembangnya masyarakat yang butuh daging ayam.

\section{Pengaruh Variabel Keterampilan Peternak}

Koefisien regresi variabel keterampilan $-0,091$, berarti petemak yang keterampilannya tinggi dalam usaha temak ayam ras pedaging, lebar rendah curahan waktu kerjanya 0,091 kali dibandingkan dengan petemak yang keterampilannya rendah. Kemudian t hitung $=-1,403$ lebih besar dibandingkan dengan $t$ tabel pada taraf kepercayaan $90 \%=.1,746$, sehingga terima hipotesa Ho, berarti; terdapat perbedaan yang tidak nyata antara curahan waktu kerja peternak yang keterampilannya tinggi dengan petemak yang keterampilannya rendah. Hasil tersebut disebabkan karena; petemak yang keterampilannya tinggi lebih banyak memberikan petunjuk dan pengarahan kepada tenaga kerjanya. Akibatnya pekeljaan lebm banyak dikeljakan oleh tenaga kerjanya.

\section{KESIMPULAN DAN SARAN}

1. Peternak umumnya memiliki pengetahuan yang tinggi tentang usahanya sehingga mereka mudah memahami teknologi seperti teknik pemberian pakan dan obat-obatan. Sikap petemak sangat serius dalam bekerja dan meyakini usahanya akan berkembang pada masa datang serta mereka berharap adanya upaya-upaya pengembangan usahanya. Keterampilan bekerja mereka sudah tinggi sehingga pekeljaan yang sulit seperti mendirikan dan memperbaiki kandang sudah dapat dilakukan.

2. Petemak ayam ras pedaging di daerah ini umumnya; dalam usia produktif sehingga tenaganya masih kuat dalam bekerja. Tanggungan keluarganya masih sedikit sehingga belum memberatkan biaya hidup keluarganya. Ada dua orang anggota keluarga yang membantu dan memperlancar kegiatan usaha. Pengalaman berusaha belum cukup tinggi namun telah memiliki keterampilan cukup memadai. Pendidikan banyak yang tamat SMA sehingga petemak mudah memahami petunjuk teknis dalam mengelola usaha temak. Luas kandang yang dimiliki tergolong besar namun kapasitasnya belum digunakan secara maksimal. Curahan waktu kerja yang paling banyak pada saat pemeliharaan ayam.

3. Secara komulatif faktor sosial ekonomi dan aspek perilaku mempengaruhi peningkatan 
curahan waktu kelja. Namun secara parsial faktor yang mempengaruhi peningkatan curahan waktu kerja adalah umur, jumlah tenaga kerja dan biaya produksi. Curahan waktu kerja yang tinggi terjadi pada petemak yang pengetahuan dan keterampilannya tinggi.

\section{SARAN}

Disarankan agar petemak di daerah ini senantiasa diberikan pembinaan dari mitra peminjam modal dan dinas petemakan yang bertujuan untuk meningkatkan pengetahuan dan keterampilan petemak dalam mengelola usahanya. Menurut keterangan dari beberapa petemak pembinaan tersebut kurang mereka dapatkan.

\section{DAFTAR PUSTAKA}

Ismono, HR (1997). Beberapa Faktor Sosial Ekonomi yang Mempengaruhi Curahan Kerja Rumah Tangga Petani Padi Sawah pada Lahan Irigasi dan Tadah Hujan di Kabupaten Lampung Tengah. Jurnal Sosio Ekonomika. 3(6): Universitas Lampung.

Ismono, HR dan Aring, HL (1997). Alokasi Curahan Kelja Rumah Tangga Petani Padi Sawah pada Beberapa Kwalitas Lahan Sawah di Kabupaten Lampung Tengah. Jurnal Sosio Ekonomika. 3 (5); ;Universitas Lampung.

Martin, E. et all (1990) Analisis Pendugaan Faktor Produksi pada Petemakan Ayam Ras Petelur di Kotamadia Bandar Lampung. Jumal Penelitian Fakultas Pertanian Universitas Lampung. 2 (3) ;

Mutmaidah, S. 2002. Analisis Fungsi Keuntungan dan Resiko Usaha Petemakan Ayam Ras Pedaging di Kecamatan Selebar Kota Bengkulu. Skripsi Mahasiswa Jurusan Sosial Ekonomi Pertanian Fakultas Pertanian Universitas Bengkulu.

Nurmanaf, 1989. Alokasi Curahan Tenaga Kelja Rumah Tangga Pedesaan Di Lampung. Dalam Prosding Patanas: Perkembangan Struktur Produksi, Ketenagakerjaan dan Pendapatan Rumah Tangga Pedesaan. Pusat Penelitian Agro Ekonomi Badang Penelitian dan Pengembangan Pertanian Departemen Pertanian, Bogor.

Purwaty, D. (1997). Analisis Curahan Tenaga Kerja dan Pendapatan Usaha Temak Sapi Perah Di Desa Gisting Atas Talang Padang Lampung Selatan. Jurnal Sosio Ekonomika. 9 (2) ; Universitas Lampung.

Sayuti, RH, 1998. Pengaruh Program Konservasi Lahan Kering Tehadap Perilaku Petani di Kabupaten Lombok Barat. Jurnal Penelitian UNRAM I (18) ; Universitas Mataram.

Waspodo, S dan Hilyana, S. 1998. Studi Perilaku Petani Terhadap Teknologi Konservasi pada Lahan Kritis Kasus di Kecamatan Aikmel. Jumal Penelitian UNRAM I (18) ; Universitas Mataram. 